\title{
Study of serum beta-HCG in second trimester as predictor of preeclampsia
}

\author{
Tripti Markam ${ }^{1 *}$, Ishita Priyam Singh², Bharati Misra ${ }^{3}$ \\ 1,2Post Graduate resident, 3 Professor and HOD, Department of Obstetrics and Gynaecology, M.K.C.G. Medical college, Berhampur, Odisha, \\ India. \\ Email: trips.143@gmail.com
}

Abstract Background: Hypertensive disorders in pregnancy are one of the major causes of maternal morbidity and mortality. Hypertensive disorders in pregnancy account for $14 \%$ of all maternal deaths. An ideal predictor of the disease, the application of which could significantly alter the associated morbidity and mortality, remains elusive. Aim and objective: To study whether raised maternal serum beta hCG in second trimester is associated with increased incidence of Preeclampsia Methodology: 450 antenatal women carrying singleton pregnancy, fulfilling all inclusion and exclusion criteria were included in our prospective observational study. One venous sample were collected from each patient for beta hCG between 12-20 weeks. Patients followed up upto delivery. Outcome measured as development of preeclampsia during pregnancy. All relevant patient data and investigations were analysed statistically using Statistical version 16 [SPSS]. Results and discussion: The incidence of Preeclampsia was $26.88 \%$ in our study. In our study among 450 women, 121 developed PE with cut-off value of beta hCG value $>82500 \mathrm{mIU} / \mathrm{ml}$. The cut-off value for overall PE group and for mild preeclampsia group are same as $82500 \mathrm{mIU} / \mathrm{ml}$.

Key Word: serum beta-HCG.

\section{*Address for Correspondence:}

Dr Tripti Markam, Post Graduate Resident, Department of Obstetrics and Gynaecology, M.K.C.G. Medical college, Berhampur, Odisha, India. Email: trips.143@gmail.com

Received Date: 23/03/2020 Revised Date: 18/05/2020 Accepted Date: 11/06/2020

DOI: https://doi.org/10.26611/10121511

This work is licensed under a Creative Commons Attribution-NonCommercial 4.0 International License. $(\mathbf{c c})$ EY-NC

\begin{tabular}{|l|l|}
\hline \multicolumn{2}{|c|}{ Access this article online } \\
\hline Quick Response Code: & $\begin{array}{l}\text { Website: } \\
\text { www.medpulse.in }\end{array}$ \\
\cline { 2 - 2 } & $\begin{array}{r}\text { Accessed Date: } \\
\text { 03 July 2020 }\end{array}$ \\
\hline
\end{tabular}

\section{INTRODUCTION}

Preeclampsia is a potentially serious complication of pregnancy with increasing significance worldwide. Preeclampsia is a cause of $9-26 \%$ of global maternal mortality and a significant proportion of preterm delivery and maternal and neonatal morbidity. Worldwide preeclampsia and eclampsia are responsible for approximately $14 \%$ of maternal death per year. ${ }^{1}$ In India the prevalence of preeclampsia is $8 \%$ and it is second most common cause of maternal death after haemorrhage. ${ }^{2}$ Beta hCG is a glycoprotein, its molecular weight is $36000-$ 40000 dalton. It consist alpha and beta subunits having 92 and 145 amino acid. ${ }^{3}$ Alpha subunit is biochemically similar to LH, FSH and TSH, where beta subunit is relatively unique to hCG. hCG is chemically and functionally similar to pituitary leutinizing hormone. ${ }^{4}$ Placental GnRH have control on hCG formation. Doubling Time of beta-hCG is $1.4-2$ Days, The blood and urine value reaches maximum level ranging from 100-200 IU/ml between $60-70$ days of pregnancy. ${ }^{4}$ Half life is 36 hours. The concentration falls slowly reaching a low levels of 10$20 \mathrm{IU} / \mathrm{ml}$ between 100-130 days, there after level remains constant throughout pregnancy with a slight secondary peak at 32 weeks. Normal level of hCG in nonpregnant state- $5 \mathrm{mIU} / \mathrm{ml}$, pregnant state- $>25 \mathrm{IU} / \mathrm{ml}$ and in postmenopausal women- upto $14 \mathrm{IU} / \mathrm{ml} .{ }^{5}$ In most normal pregnancy at hCG level below $1200 \mathrm{mIU} / \mathrm{ml}$ the hCG levels usually doubles every 48-72 hours and normally increases by at least $60 \%$ every two days. In early pregnancy, a 48 hours increase of hCG by $35 \%$ can still be considered normal. ${ }^{6}$ Between 1200-6000 mIU/ml serum hCG level usually takes 72-96 hours to double. After $6000 \mathrm{mIU} / \mathrm{ml}$ it takes over four or more days to double. ${ }^{7-9}$ When it reaches $7200 \mathrm{mIU} / \mathrm{ml}$ a yolk sac and in $10,800 \mathrm{mIU} / \mathrm{ml}$ or greater than that a visible embryo with heart beat should be seen. ${ }^{10}$ Immunological response in preeclampsia developes in two 
stages. 1.Abnormal placentation and spiral artery remodelling - This is due to decreased placental HLA-G expression. HLA-G has a major role in placentation and blood flow development as observed in a normal pregnancy. There is a failure of extravillous trophoblast invasion and spiral artery remodelling. This is due to failure of interaction of extravillous trophoblast with uterine NK-cells and HLA-C receptors. ${ }^{11}$ 2.PreeclampsiaIt is associated with widespread systemic inflammation and endothelial dysfunction. The immune dysfunction are as follows:- There is decreases in regulatory T-cells both in number and function. There is insufficient shift from TH1 to TH2 as opposed to normal pregnancy where Th2 predominance is observed. There is a higher level of cytokinin abnormality with increased concentration of TNF-alpha, IL-6, IL-1beta, IL-8 and lower concentration of IL-10. In preeclampsia there is abnormal maternal-fetal immune interaction. Present study was conducted to see whether raised maternal serum beta $\mathrm{hCG}$ in second trimester is associated with increased incidence of Preeclampsia.

\section{MATERIAL AND METHODS}

Present study was a Prospective observational study conducted in Department of OBGY, MKCG Medical College and hospital Berhampur during 2016-2018. Study population was Patient attending antenatal clinic of the department of obstetrics and gynaecology of MKCG Medical College and hospital Berhampur. Most of these patients came from in and around Ganjam district and consisted of both urban and semi urban population. The patients were mainly from low and middle income socioeconomic groups.

Inclusion criteria: All antenatal patients between $12-20$ weeks (as determined by LMP or Dating USG scan) with singleton pregnancy. 2. Patients willing to participate in the study

Exclusion criteria: 1. Patients With multiple pregnancy 2. Patients With chronic hypertension or Known cases of diabetes mellitus 3. Patients With congenital anomalies 4. Patients With hydatidiform mole 5. Patients With intrauterine fetal disease 6. Patients who were Known case of hypothyroid or renal disease A total of 480 cases were selected out of which 450 patients completed the study and were followed till the end. Study was approved by ethical committee of the institute. A valid written consent was taken from patients after explaining study them. Data was collected with pre tested questionnaire. Data included demographic data, clinical history. A through clinical examination was done. Under aseptic precaution sampling was done by venipuncture, $5 \mathrm{ml}$ of blood was drawn out of which $3 \mathrm{ml}$ of blood was used for routine investigations and $2 \mathrm{ml}$ of Blood for special investigations. Samples were collected once between 12-20 weeks. Serum $\beta$ - hCG level was done by CLIA method (Chemiluminescence Immunoassay) between 12-20 weeks. Regular Blood Pressure monitoring with the same sphygmomanometer which is regularly calibrated was used. Blood Pressure measurement was done in semi supine position. The width of the cuff was kept large to avoid over diagnosis of hypertension. Keeping the rate of deflation to $2-3 \mathrm{~mm} \mathrm{Hg}$ also prevented over diagnosing diastolic hypertension. Patients were followed up and outcome was noted. Data analysed with appropriate statistical tests.

\section{RESULTS}

Most of the patients (51.11\%) attending the Antenatal clinic and included in our study were in the age group 2025 years. Most of the patients $(72.18 \%)$ in the study population were primigravida. Of the 450 patients followed, 121 women developed PE constituting a $26.88 \%$ of the study population. Thus, the incidence of Preeclampsia was $26.88 \%$ in our study. (table 1) When further subdivided, Out of these 121 Preeclamptic patients, 24 women had Early onset preeclampsia (onset $<34$ weeks) whereas rest 97 had late onset ( $>34$ weeks) disease. About 60\% women belonging to PE group had preterm delivery compared to $21 \%$ in case of normotensive group. These values were tabulated and analysed using Fischer's exact test 2-tailed and the $p$ value was statistically significant Majority of the women who developed PE were primigravida (about 78\%). Only $21 \%$ of preeclamptic women were multipara.

In our study we found that serum beta hCG were elevated in PE, more significantly elevated in severe PE when compared with normotensive group. This indicates that there exists an abnormal secretary function of the placenta in cases of PE.

In our study among 450 women, 121 developed PE with cut-off value of beta hCG value $>82500 \mathrm{mIU} / \mathrm{ml}$. From ROC Curve analysis, Curve no- 1, it was found that for early second trimester(12-20weeks) beta hCG value above $82500 \mathrm{mIU} / \mathrm{ml}$, Sensitivity was $99.2 \%$ and specificity was $100 \%$ with a positive likelihood ratio of $\infty$ and negative likelihood ratio of 0.008 .

Next from ROC Analysis, Curve no -2, among mild PE group found that second trimester beta hCG value above $82500 \mathrm{mIU} / \mathrm{ml}$, Sensitivity was $96.90 \%$ and specificity was $78.70 \%$, with a positive likelihood ratio of 4.55 and negative likelihood ratio of 0.04. Lastly from ROC Analysis, Curve no -3, among severe PE group found that second trimester beta hCG value above $99950 \mathrm{mIU} / \mathrm{ml}$, Sensitivity was $98.90 \%$ and specificity was $98.10 \%$, with a positive likelihood ratio of 50.99 and negative likelihood ratio of 0.011 . 
Table 1: Distribution of patients according to development of PE

\begin{tabular}{ccc}
\hline GROUP & NO OF PATIENTS & $\%$ \\
\hline PE & 121 & $26.88 \%$ \\
NORMOTENSIVE & 329 & $73.11 \%$ \\
\hline Total & 450 & $100 \%$ \\
\hline
\end{tabular}

Table 2: Distribution of patients according to severity of PE

\begin{tabular}{ccc}
\hline PREECLAMPSIA & NO OF PATIENTS & $\%$ \\
\hline MILD & 32 & $26.44 \%$ \\
SEVERE & 89 & $73.55 \%$ \\
\hline Total & 121 & $100 \%$ \\
\hline
\end{tabular}

Table 3: comparison of PE and Normotensive patients according to gestational age

\begin{tabular}{cccc}
\hline GROUPS & PRETERM & TERM & Total \\
\hline GROUP 1 (PE) & 72 & 49 & 121 \\
GROUP 2 (NORMOTENSIVE) & 68 & 261 & 329 \\
\hline Total & 140 & 310 & 450 \\
\hline
\end{tabular}

Table 4: Statistical analysis according to mean B-HCG and age of patients (450)

\begin{tabular}{cccccccccc}
\hline & VALID N & MEAN & MEDIAN & MINIMUM & MAXIMUM & $\begin{array}{c}\text { LOWER } \\
\text { QUART. }\end{array}$ & $\begin{array}{c}\text { UPPER } \\
\text { QUART. }\end{array}$ & STD DEV & STD ERROR \\
\hline AGE & 450 & 24.64 & 24.00 & 19.00 & 35.00 & 21.00 & 28.00 & 4.157 & 0.196 \\
BHCG1 & 450 & 60922.97 & 35200 & 7200 & 220000 & 25600.00 & 91197.50 & 54679.156 & 2577.600 \\
\hline
\end{tabular}

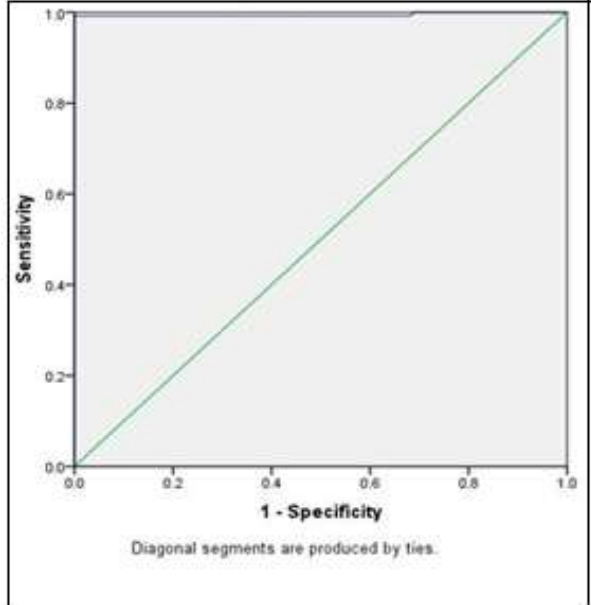

ROC curve 1

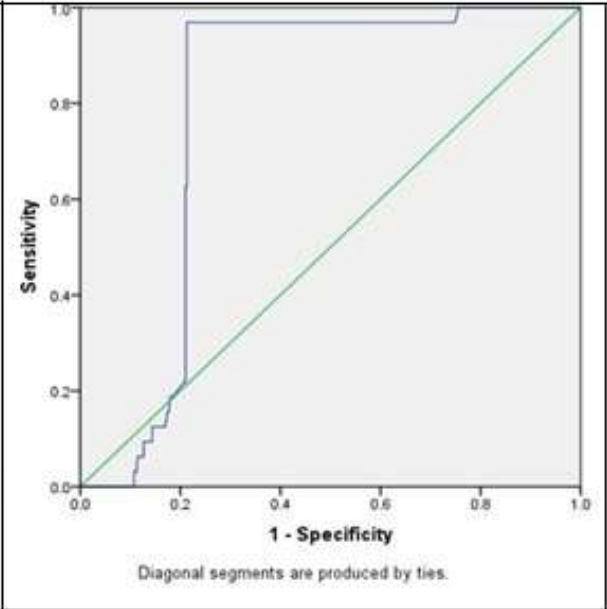

ROC curve 2

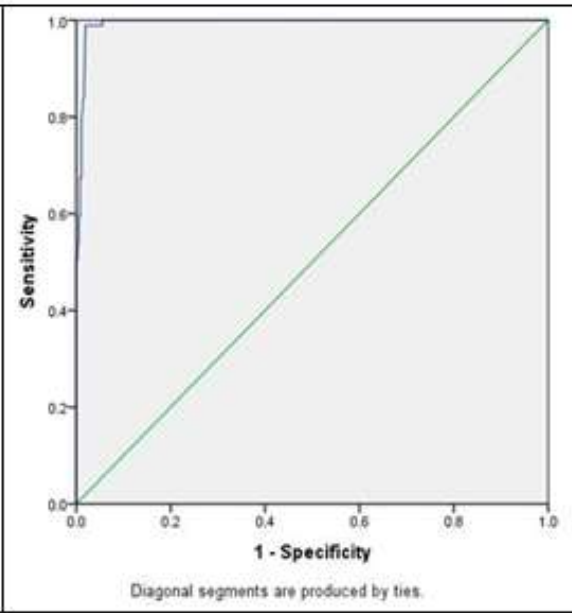

ROC curve 3

ROC curve 1: ROC curve analysis for predicting PE on the basis of BHCG( 12-20 weeks); ROC curve 2: ROC curve analysis for predicting mild PE on the basis of BHCG( 12-20 weeks); ROC curve 3: ROC curve analysis for predicting severe PE on the basis of BHCG( 12-20 weeks)

Table 1: ROC Curve 1

\begin{tabular}{lll}
\hline \multicolumn{1}{c}{ Variable } & BHCG \\
\hline Classification variable & PE \\
Sample size & 450 \\
Positive group : & PE =1 & 121 \\
Negative group : & PE $=0$ & 329 \\
Disease prevalence (\%) & Unknown \\
Area under the ROC curve (AUC) & 0.994 \\
Standard Error & 0.006 \\
95\% Confidence Interval & 0.983 to 1.000 \\
z statistic & 1.960 \\
Significance level P (Area=0.5) & 0.0001 \\
\hline
\end{tabular}


Table 2: ROC Curve 2

\begin{tabular}{lcc}
\hline \multicolumn{1}{c}{ Variable } & BHCG \\
\hline Classification variable & MILD PE \\
Sample size & 450 \\
Preeclampsia patients : & PE =1 & 121 \\
Mild Preeclampsia : & PE $=0$ & 32 \\
Disease prevalence (\%) & Unknown \\
Area under the ROC curve (AUC) & 0.785 \\
Standard Error & 0.026 \\
95\% Confidence Interval & 0.983 to 1.000 \\
z statistic & 1.960 \\
Significance level P (Area=0.5) & 0.0001 \\
\hline
\end{tabular}

\begin{tabular}{lll}
\multicolumn{2}{c}{ Table 3: ROC Curve 3 } \\
\hline \multicolumn{2}{c}{ Variable } & \multicolumn{1}{c}{ BHCG } \\
\hline Classification variable & SEVERE PE & \\
Sample size & & 450 \\
Preeclampsia patients : & PE $=1$ & 121 \\
Severe Preeclampsia : & PE $=0$ & 89 \\
Disease prevalence (\%) & & Unknown \\
Area under the ROC curve (AUC) & 0.994 \\
Standard Error & & 0.004 \\
95\% Confidence Interval & & 0.99 to 1.000 \\
z statistic & 1.960 \\
Significance level P (Area=0.5) & 0.0001 \\
\hline
\end{tabular}

\section{DISCUSSION}

In our study of 450 patients, 121 patients developed Preeclampsia and rest 329 remained normotensive. The incidence of PE in our study was $26.88 \%$. In their study of 164 cases, Vidyabati et al. found prevalence rate of PIH as $17.68 \% 114$. Yadav et al. reported an incidence of PIH of $17.5 \%$ in $2014 .{ }^{12}$ Majority of the women who developed PE were primigravida (about $78 \%$ ), in accordance with studies by other authors. Only $21 \%$ of preeclamptic women were multipara. Redman suggested that in later pregnancies there is development of protective immunologic mechanisms against paternal antigens. ${ }^{13} \mathrm{In}$ an overview by Zuspan et al. PIH occurs mainly in primiparous women (85\%), who have 4-5 times higher risk than multiparous women. ${ }^{14}$ About $60 \%$ women belonging to PE group had preterm delivery compared to $21 \%$ in case of normotensive group. A prospective study done by $\mathrm{Ye}$ RW et al. ${ }^{15}$ in China showed that PIH leads to preterm delivery and iatrogenic prematurity caused due to the necessity to terminate pregnancy. In our study among 450 women, 121 developed PE with cut-off value of beta $\mathrm{hCG}$ value $>82500 \mathrm{mIU} / \mathrm{ml}$. From ROC Curve analysis, Curve no- 1 , it was found that for early second trimester (1220weeks) beta hCG value above $82500 \mathrm{mIU} / \mathrm{ml}$, Sensitivity was $99.2 \%$ and specificity was $100 \%$. Among mild PE group found that second trimester beta hCG value above $82500 \mathrm{mIU} / \mathrm{ml}$, Sensitivity was $96.90 \%$ and specificity was $78.70 \%$, with a positive likelihood ratio of 4.55 and negative likelihood ratio of 0.04 . Among severe PE group found that second trimester beta hCG value above 99950 $\mathrm{mIU} / \mathrm{ml}$, Sensitivity was $98.90 \%$ and specificity was $98.10 \%$, with a positive likelihood ratio of 50.99 and negative likelihood ratio of 0.011 . Here the cut-off value for overall $\mathrm{PE}$ group and for mild preeclampsia group are same as $82500 \mathrm{mIU} / \mathrm{ml}$, it showes that this test is highly effective to diagnose PE, so it can be considered as a marker for prediction of $\mathrm{PE}$ in second trimester of pregnancy. This is similar to findings by Vidyabati et al. ${ }^{16}$ in 2010 that second trimester serum beta hCG levels increased significantly in those women who developed $\mathrm{PIH}$ and it has a predictive value. More recently, a California based study conducted by Towner $\mathrm{D}$ et al. ${ }^{17}$ and TacheV et al. ${ }^{18}$ in 2014 shows that adverse pregnancy outcome in terms of $\mathrm{PIH} /$ preeclampsia is more in women with elevated values although no specific cut off values have been mentioned in either study. Davidson EJ et al. ${ }^{19}$ in a retrospective case-control study in 2003, noted small but significant elevations in the concentrations of beta hCG in the second trimester serum of women who subsequently developed pregnancy-induced hypertension and preeclampsia.

However, studies by Yadav K et al. ${ }^{20}$ and Pouta et al. ${ }^{21}$ did not observe any correlation between levels of beta hCG and development of PIH. The divergent points of maternal serum beta hCG with wide range of cut off values may be responsible for this result. 


\section{CONCLUSION}

Measuring serum beta hCG in early second trimester (1220 weeks) is a useful indicator to identify women who are likely to develop PE in the same pregnancy. Serum beta $\mathrm{hCG}$ value $>82500 \mathrm{mIU} / \mathrm{ml}$ can be considered as marker for predicting preeclampsia in second trimester of pregnancy. Also high levels are associated with increased severity of preeclampsia.

\section{REFERENCES}

1. Lale Say,Doris chow.Global cause of maternal death:WHO systemic analysis. 2014

2. Sutupa Agarwal, Gagandeep K Walia.National Family Health Survey.2014

3. Glycoprotein hormones alpha chain precursor- Homo Sapience(Human) Uniprot accession number PO1215(25116)

4. Brian $\mathrm{Wu}$ and Kathryn Watson, Human chorionic gonadotropin (hCG) blood test.16.03.2018

5. Barker DJ.Fetal origin of coronary heart disease.BMJ.1995;311(6998):171-4

6. Kirk E,Bottomley C, Bourne $\mathrm{T}$.Diagnosis ectopic pregnancy and current conceps in the management of pregnancy of unknown location. Human Reproduction Update,20(2):250-61

7. Ashitaka Y et al.. Production and secretion of hCG and hCG subunits by trophoblastic tissue.In Segal S : chorionic gonadotropin, New York,Plenum,1980 p 151

8. Pittawy DE et al. . Doubling times of human chorionic gonadotropin increases in early viable intrauterine pregnancy.Am J Obstet Gynecol 1985;299-302

9. American College of Obstetrician and Gynaecologists.Medical management of Tubal pregnancy.Practice Bulletin no 3,December 1998.Washington D.ACOG, 1998

10. Giacomello F,Magliocchetti P,Loyola G,Giovarruscio M (1993) .Serum beta hCG levels and transvaginal echography in the early phases of pregnancy.Minerva Ginecol(In Italian).45(7-8):333-7
11. Ward K, Lindheimer MD: Genetic factors in the etiology of preeclampsia/eclampsia. In Lindheimer MD, Roberts JM, Cunningham FG (Eds): Chesley's Hypertensive Disorders in Pregnancy, 3rd ed. Elsevier, In press, 2009, p51.

12. Ehrenthal DB, Jurkovitz C, Hoffman M, Jiang X, Weintraub WS.Prepregnancy body mass index as an independent risk factor for pregnancy-induced hypertension.J Womens Health (Larchmt). 2011 Jan;20(1):67-72

13. John JH, Ziebland S, YudkinP, etal:Effectsof fruits and vegetable consumption on plasma antioxidant concentrations and blood pressure: A randomized controlled trial. Lancet359:1969, 2002

14. Vidyabati R K ,HijamDevina, Singh NK, Singh N Gyaneswar. J. ObstetGynecol India Vol-60, No. 1 : January / February 2010 pg 44-50.

15. Slattery MM, Morrison JJ. Preterm Delivery. Lancet 2002; 360: 1489-9798.

16. Vanitha V,Shanthi S,S Usha Rani.To study the role of maternal serum beta hCG at 13-20 weeks of gestation in prediction of preeclampsia.Indian Journal of Research,(December 2016) volume-5

17. Tuffnell DJ, Jankowicz D, Lindow SW et al.. Outcome of severe preeclampsia/eclampsia. Br J ObstetGynecol 2005; $112: 875-80$

18. Towner D, Gandhi S, Dina El Kady, et al.. Obstetric outcomes in women with elevated maternal serum human chorionic gonadotropin. American Journal of Obstetrics andGynecologyVolume 194, Issue 6, Pages 1676-1681, June 2006.

19. De J, Mukhopadhyay A, Saha PK. Study of serum lipid profile in pregnancy induced hypertension. Indian J Clin Biochem.2006;21(2):165-8.

20. Fox H,Khorkongor FN.Immunofluorescent localization of chorionic gonadotrophin in the placenta and in the tissue culture of human trophoblast.J Pathol 101:277-82,1970.

21. Pouta AM, Hartikainen AL, Vuolteenaho O J ,Ruokonen AO et al. . Mid trimester N-terminal proatrial natriuretic peptide, free beta $\mathrm{Hcg}$, and alpha - fetoprotein in predicting preeclampsia. ObstetGynecol .1998; 91: 940944.

\section{Source of Support: None Declared Conflict of Interest: None Declared}

Policy for Articles with Open Access:

Authors who publish with MedPulse International Journal of Gynaecology, (Print ISSN: 2579-0870) (Online ISSN: 2636-4719) agree to the following terms: Authors retain copyright and grant the journal right of first publication with the work simultaneously licensed under a Creative Commons Attribution License that allows others to share the work with an acknowledgement of the work's authorship and initial publication in this journal.

Authors are permitted and encouraged to post links to their work online (e.g., in institutional repositories or on their website) prior to and during the submission process, as it can lead to productive exchanges, as well as earlier and greater citation of published work. 